Research paper

\title{
Impact of baseline cytogenetic findings and cytogenetic response on outcome of high-risk myelodysplastic syndromes and low blast count AML treated with azacitidine
}

\author{
Marie Sébert $^{\mathrm{a}, \mathrm{b}, 1}$, Rami S Komrokji ${ }^{\mathrm{c}, 1}$, Mikkael A. Sekeres ${ }^{\mathrm{d}}$, Thomas Prebet ${ }^{\mathrm{b}, \mathrm{e}}$, Thomas Cluzeau ${ }^{\mathrm{b}, \mathrm{f}}$, \\ Valeria Santini $^{\mathrm{g}}$, Emmanuel Gyan ${ }^{\mathrm{b}, \mathrm{h}}$, Alessandro Sanna ${ }^{\mathrm{g}}$, Najla HAl Ali ${ }^{\mathrm{c}}$, Sean Hobson ${ }^{\mathrm{d}}$, \\ Virginie Eclache ${ }^{\mathrm{b}, \mathrm{i}}$, Alan List ${ }^{\mathrm{c}}$, Pierre Fenaux ${ }^{\mathrm{a}, \mathrm{b}}$, Lionel Adès ${ }^{\mathrm{a}, \mathrm{b}, *}$ \\ a Service d'hématologie clinique, Hôpital Saint-Louis, Paris, France \\ ${ }^{\mathrm{b}}$ Groupe Francophone des Myélodysplasies, Paris, France \\ ${ }^{c}$ Malignant Hematology, H. Lee Moffitt Cancer Center \& Research Institute, Tampa, FL, United States \\ d Leukemia Program, Hematologic Oncology and Blood Disorders, Cleveland Clinic Taussig Cancer Institute, Cleveland, OH, United States \\ e Service d'hématologie clinique, Institut Paoli Calmettes, Marseille, France \\ ${ }^{\mathrm{f}}$ Nice côte Azur Univeristy, Nice Sophia Antipolis University, CHU of Nice, INSERM U1065, Mediterranean Center of Molecular Medicine, Nice, France \\ ${ }^{g}$ Hematology, AOU Careggi, University of Florence, Florence, Italy \\ ${ }^{\text {h }}$ Hématologie et thérapie cellulaire, CHU de Tours, UMR CNRS 7292, Université de François Rabelais, Tours, France \\ i Laboratoire d'hématologie biologique, Hôpital Avicenne, Bobigny, France
}

\section{A R T I C L E I N F O}

\section{Keywords:}

MDS

Azacitidine

Cytogenetics

Cytogenetic response

Prognosis

\begin{abstract}
A B S T R A C T
Karyotype according to the revised IPSS is a strong independent prognostic factor for overall survival (OS) in myelodysplastic syndromes (MDS), however established in untreated patients. The prognostic impact of cytogenetics and cytogenetic response (CyR) in MDS patients receiving azacitidine (AZA) remains uncertain. We examined the prognostic value of baseline cytogenetics and CyR for overall response rate (ORR) and OS in 702 AZA-treated higher risk MDS and low blast count acute myeloid leukemia (AML), including 493 (70\%) with abnormal karyotype. None of the cytogenetic abnormalities had significant impact on ORR (43.9\%) or complete response (15.35\%), except 3q abnormalities and complex karyotypes, which were associated with a lower ORR. OS differed significantly across all R-IPSS cytogenetic subgroups $\left(\mathrm{p}<10^{-4}\right)$ but patients with non complex del (7q) had similar survival as patients with normal cytogenetics. CyR was achieved in $32 \%$ of the 281 evaluable patients with abnormal cytogenetics, was complete (CCyR) in 71 (25.3\%) patients. We found no correlation between hematological response and cytogenetic response and $21 \%$ of the patients with CCyR did not achieve morphological response. In the 281 patients, we found no impact of CyR on survival, but when restricting to MDS (ie: < 20\% marrow blasts) achievement of CCyR was associated with better OS.
\end{abstract}

\section{Introduction}

Myelodysplastic syndromes (MDS) are clonal stem cell disorders characterized by ineffective hematopoiesis resulting in blood cytopenias, and by a high risk of progression to acute myeloid leukemia (AML) [1]. Cytogenetic abnormalities are found in about $50 \%$ of MDS patients, consisting mainly of complete or partial loss of chromosomes 5,7 , and 20 (del(5q), -7, del(7q), del(20q)), chromosome gains (especially +8 ), or complex karyotypes [11]. Cytogenetic findings were incorporated as prognostic markers in MDS in the classical International Prognostic Scoring System (IPSS) [9]. In the recent revised version of the IPSS (IPSS-R), based on 7012 patients, cytogenetic prognostic classification could be refined in five instead of three prognostic subgroups, and the prognostic "weight" of cytogenetics was increased compared to that of other parameters $[10,18]$. However, this IPSS-R cytogenetic classification was established in untreated patients.

The hypomethylating agent (HMA) azacitidine (AZA) improves survival, and has become a reference treatment of higher risk MDS and low blast count AML patients not candidates for intensive chemotherapy or allogeneic stem cell transplantation [7]. A feature of HMAs therapy is that a survival benefit may occur in the absence of complete or partial response (CR, PR), i.e. that patients who only

\footnotetext{
* Corresponding author at: Service d'hématologie clinique Hôpital Saint-Louis, 1 avenue Claude vellefaux, 75010 Paris, France.

E-mail addresses: marie.sebert@gmail.com (M. Sébert), lionel.ades@aphp.fr (L. Adès)

${ }^{1}$ These authors contributed equally to the study and should be considered as first co-authors.
} 
improve their cytopenias (stable disease with hematological improvement or HI, according to IWG 2006 response criteria) also have a survival benefit [8]. Prognostic factors of response and survival with AZA treatment are still incompletely known. Regarding karyotype, it has been suggested in relatively small series that unfavorable karyotypes, including monosomy 7 and complex karyotype, were associated with good response rates, although survival remained shorter than in patients with more favorable cytogenetics $[16,17]$. Whether cytogenetic findings, and in particular IPSS-R cytogenetic classification, can predict outcome in large series of MDS patients receiving HMAs, remains to be determined. Moreover, while cytogenetic response is an important independent prognostic factor for outcome in chemotherapy-treated AML patients [5], only one paper evaluated cytogenetic response in AZAtreated MDS patients [12]. In that study evaluating low or high risk MDS patients treated with HMA (mainly Decitabine) achievement of complete cytogenetic response was associated with survival improvement [12].

In the present study, we analysed the prognostic value of baseline cytogenetic characteristics (including IPSS-R cytogenetic classification) on response to treatment and survival, and the prognostic impact of cytogenetic response, in 702 patients with higher risk MDS and low blast count AML (20-30\% blasts) treated with Azacitidine in seven centers over an 11-year period.

\section{Patients and methods}

\subsection{Patient selection}

Patients with Higher Risk MDS, AML $<30 \%$ blasts or chronic myelomonocytic leukemia (CMML) having received at least one cycle of azacitidine, started between October 2002 and March 2013 in the seven participating centers, were eligible. Low blast count AML (with 20-30\% marrow blasts) was included, as azacitidine is approved in this patient subset in most countries. Participating centers were the Lee Moffitt Cancer center Institute, Tampa; Cleveland Clinic Taussig Cancer Institute, Cleveland, $\mathrm{OH}$; Groupe francophone des myélodysplasies (GFM) including centers of hôpital Avicenne, Institut Paoli Calmettes, Marseille, university hospitals of Nice and Tours), and Universita di Firenze, Italy. This study was conducted in accordance with the Declaration of Helsinki.

A total of 702 Higher Risk MDS patients and low blast count AML were included in the analysis, excluding only AML patients with $\geq 30 \%$ marrow blasts and patients previously treated with intensive chemotherapy or allogeneic stem cell transplantation.

\subsection{Cytogenetic analysis}

Cytogenetic analysis was performed using standard chromosomes banding techniques and documented according to ISCN 2013 recommendations [19]. Twenty metaphases were required. When necessary, Fluorescent In Situ Hybridization (FISH) was made to assess a specific cytogenetic abnormality. Cytogenetic results were classified according to IPSS [9] and IPSS-R cytogenetic classifications [18]. Monosomal karyotype was defined as the presence of at least two autosomal monosomies or of a single monosomy associated with at least one structural abnormality [4].

\subsection{Treatment}

Azacitidine was generally administered as a single agent outside a clinical trial at the approved EMA/FDA approved schedule $\left(75 \mathrm{mg} / \mathrm{m}^{2}\right.$ / day for seven consecutive days or according to the 5-2-2 schedule, every 28 days) until disease progression, unacceptable toxicity, or patient decision. Patients older than 80 or with comorbidities, however, often received lower doses. Response was evaluated after four-six cycles by blood count, marrow aspirate and cytogenetic analysis.

\subsection{Study endpoints}

CR, PR, marrow CR (mCR), stable disease (SD), hematological improvement (HI), progression, were defined according to IWG 2006 criteria [6]. Complete cytogenetic response (CCyR) was defined as disappearance of a cytogenetic abnormality, requiring 20 analysable metaphases, and partial cytogenetic response (PCyR) as a $50 \%$ or more reduction of the number of abnormal metaphases [6]. Overall survival (OS) was measured from the onset of AZA.

\subsection{Statistical analysis}

Predictive factors for response were analysed using Fisher's exact test for univariate comparisons. Univariate analyses were performed with log-rank tests. Outcomes of patients with specific chromosomal abnormalities were compared with those of the normal karyotype group. All p values were 2-tailed. A landmark analysis on the impact of cytogenetic response was performed at three and six months, in all the patients with abnormal cytogenetics at the onset of the treatment and with evaluable cytogenetic analysis at treatment evaluation. All analyses were performed with Stata/SE Version 12.

\section{Results}

\subsection{Baseline characteristics of the study population}

The 702 MDS or low blast count AML patients included in the study had received AZA in the seven centers, started between October 2002 and March 2013. Their median age was 69 years (range 24-91), including $60 \%$ older than 65 years, and $37 \%$ were females. At onset of AZA (Table 1), WHO diagnosis was RAEB1 in 140 (19.9\%) cases, RAEB2 in 338 (48.1\%), AML with 20-30\% blast in 123 (17.5\%), RCMD in $62(8.8 \%)$, RARS in 7 (1\%), CMML in 20 (2.8\%), unclassified MDS in seven and unknown MDS type (UK) in five patients. IPSS was Int-2 in 438 (62.66\%), high in 261 (37.34\%) and NA (but at least Int-2) in three patients. IPSS-R was very low in one $(0.1 \%)$, low in $13(2 \%)$, intermediate in 97 (14\%), high in 243 (35\%), very high in 320 (45\%) and unknown in 28 patients.

\subsection{Baseline cytogenetic characteristics}

Among the 702 evaluable patients, 209 (29.8\%) had a normal karyotype. According to IPSS-R cytogenetic categories, 10 (1.4\%), 241 (34.3\%), 130 (18.5\%), $118(16.8 \%)$ and 201 (28.6\%) were classified as very good, good, intermediate, poor and very poor risk groups, respectively (two unclassified) (Table 1).

Two hundred and twenty seven patients had chromosome 7 abnormalities: 142 monosomy 7, including 29 isolated monosomy 7, 20 monosomy 7 with one additional abnormality $(+1)$, and 93 monosomy 7 complex. Fifty one patients had del(7q), including 13 patients with isolated $\operatorname{del}(7 q)$, nine $\operatorname{del}(7 q)+1$, and 29 complex with $\operatorname{del}(7 q)$. The remaining 34 chromosome 7 abnormalities were mostly (72\%) part of a complex karyotype.

Two hundred and six patients had chromosome 5 abnormalities: 126 had del(5q), including nine patients with isolated del(5q), 14 with $\operatorname{del}(5 q)+1$, and 103 complex. Thirty-nine had monosomy 5 , all but one associated with a complex karyotype. The remaining 41 chromosome 5 abnormalities were mostly (97\%) part of a complex karyotype.

One hundred and seven patients had trisomy 8, including 41 with isolated trisomy 8,16 with trisomy $8+1$, and 50 complex.

Other frequent cytogenetic abnormalities included $17 \mathrm{p}$ abnormalities in 58 patients ( 51 being part of a complex karyotype), del(3q) in 26 patients (15 part of a complex karyotype), isolated del(20q) in 15 patients, del(11q) in 24 patients (15 being part of a complex karyotype), and isolated loss of chromosome $\mathrm{Y}$ in four patients. Finally, according to IPSS-R cytogenetic classification, other isolated and other double 
Table 1

Patient characteristics at AZA onset.

\begin{tabular}{|c|c|c|}
\hline Age & Median (range) & 69 (24-91) \\
\hline \multirow[t]{2}{*}{ Gender } & Male & $442(63 \%)$ \\
\hline & Female & $260(37 \%)$ \\
\hline \multirow[t]{8}{*}{ WHO Diagnosis } & RARS & $7(1 \%)$ \\
\hline & RCMD & $62(8.83 \%)$ \\
\hline & RAEB1 & $140(19.94 \%)$ \\
\hline & RAEB2 & $338(48.15 \%)$ \\
\hline & AML $20-30 \%$ blasts & $123(17.52 \%)$ \\
\hline & Unclassified & $7(1 \%)$ \\
\hline & CMML & $20(2.85 \%)$ \\
\hline & Unknown & $5(0.71 \%)$ \\
\hline \multirow[t]{3}{*}{ IPSS } & Int-2 & $438(62.5 \%)$ \\
\hline & High & $261(37 \%)$ \\
\hline & NA but $\geq$ Int- 2 & $3(0.5 \%)$ \\
\hline \multirow[t]{6}{*}{ IPSS-R } & Very low & 1 \\
\hline & Low & $13(2 \%)$ \\
\hline & Intermediate & $97(14 \%)$ \\
\hline & High & $243(35 \%)$ \\
\hline & Very high & $320(45 \%)$ \\
\hline & NA & $28(4 \%)$ \\
\hline \multirow[t]{6}{*}{ IPSS-R cytogentic subgroup } & Very good & $10(1.4 \%)$ \\
\hline & Good & $241(34.3 \%)$ \\
\hline & Intermediate & $130(18.5 \%)$ \\
\hline & Poor & $118(16.8 \%)$ \\
\hline & Very Poor & $201(28.6 \%)$ \\
\hline & NA & 2 \\
\hline \multirow[t]{3}{*}{ Cytopenias } & Median $\mathrm{Hb}$ g/dl & $9.4(3-15.2)$ \\
\hline & Median WBC G/1 & $3(0.2-178)$ \\
\hline & Median PLT G/1 & $70(0-1000)$ \\
\hline \multirow{3}{*}{ BM blasts, \% } & $0-10$ & $269(38 \%)$ \\
\hline & $10-20$ & $331(47 \%)$ \\
\hline & $20-30$ & $102(15 \%)$ \\
\hline
\end{tabular}

WHO, World Health Organization; IPSS, International Prognostic scoring System; IPSS-R, Revised IPSS; RARS, Refractory anemia with Ring Sideroblasts; RCMD, Refractory Cytopenia with Multilineage dysplasia; RAEB1, Refractory Anemia with Excess blasts 1; RAEB2, Refractory Anemia with Excess blasts 2; AML, acute myeloid leukemia; CMML, Chronic Myelomonocytic Leukemia; Int, Intermediate; NA, Non Available; Hb, Hemoglobin; WBC, White Blood Cells; PLT, platelets; BM, Bone Marrow.

abnormalities were noted in $51(7 \%)$ and $26(3.7 \%)$ patients, respectively.

Two hundred and one patients had monosomal karyotype and 246 patients had complex karyotype ( $\geq$ three abnormalities) including 199/ $246(80.89 \%)$ very complex karyotypes according to IPSS-R (ie $>$ three abnormalities).

\subsection{Response to treatment and survival}

Patients received a median of six cycles [range 1-72] of AZA. Median follow up from onset of AZA was 44 months, and 697 patients were evaluable for response. Three hundred and six (43.9\%) patients achieved hematological response, including 107 (15.35\%) CR. At last follow-up, 518 patients had died, and median OS was 14.93 months.

\subsection{Impact of cytogenetic abnormalities on response to azacitidine}

Response according to cytogenetic features is shown in Table 2. The Overall response rate was $50.0 \%, 47.06 \%, 41.54 \%, 42.24 \%, 42.29 \%$ and the CR rate was $30.0 \%, 16.39 \%, 12.31 \%, 14.66 \%$ and $15.92 \%$ in patients with very good, good, intermediate, poor and very poor IPSS-R cytogenetic, respectively $(\mathrm{p}=0.77$ and $\mathrm{p}=0.54)$. We failed to identify any cytogenetic abnormalities associated with a different $\mathrm{CR}$ or response rate compared to normal cytogenetics, except for patients with $3 q$ abnormalities, associated with a lower ORR $(p=0.011)$. Similarly, when the analysis was restricted to patients who received six or more cycles of azacitidine, no additional cytogenetic abnormality had an impact on $\mathrm{CR} /$ response achievement, compared to patients with normal karyotypes. When the analysis was restricted to patients with BM blast $<20 \%$, patients with $3 q$ abnormalities $(5 / 25$ vs $77 / 160$, $\mathrm{p}=0.009)$ and patients with complex karyotype (81/213 vs $77 / 160$, $\mathrm{p}=0.05$ ) had a lower response rate to AZA compared with patients with normal karyotype, while other abnormalities had no impact on response or CR achievement.

\subsection{Impact of cytogenetic abnormalities on overall survival (OS)}

Univariate analysis was performed separately for each cytogenetic category, summarized in Table 2.

According to IPSS-R cytogenetic classification, OS was significantly different across all subgroups (median 20.4 months, 21.1 months, 16.2 months, 15.2 months and 10.2 months in very good, good, intermediate, poor and very poor IPSS-R cytogenetic groups respectively, $\mathrm{p}<10^{-4}$ ). Compared to patients with normal karyotype, patients with monosomy 7 , isolated (11.1 months) or not (12.5 months) had worse survival ( $\mathrm{p}=0.05$ and 0.04 , respectively). On the contrary, patients with $\operatorname{del}(7 \mathrm{q})$ alone or del $7 q+1$ had a similar OS as patients with normal karyotype. Similarly, the presence of del(20q) had no impact on OS. Patients with complex cytogenetic or $17 p$ (the latter mostly part of a complex karyotype) had worse survival than patients with NK. Finally, the presence of a $\operatorname{del}(5 q)$ was also associated with a shorter survival, but only if it was part of a complex karyotype. These findings were also found when the analysis was restricted to patients with less than $20 \%$ bone marrow blasts.

\subsection{Cytogenetic response}

Of the 493 patients with abnormal cytogenetics at the onset of AZA, 313 had cytogenetic analysis at treatment evaluation (including 32 patients who had cytogenetic failure), after four to six cycles of AZA. Among the 281 evaluable patients 71 (25.3\%) achieved CCyR, and 19 (6.7\%) PCyR, leading to an overall CyR of $32 \%$. CyR was observed across all cytogenetic subgroups and all IPSS-R cytogenetic categories, without any statistical difference. Even among patients with complex karyotype evaluable for cytogenetic response, 41/134 (30.6\%) achieved CCyR. Surprisingly, among the 71 patients who achieved CCyR, 21\% did not achieve morphological response according to IWG 2006 criteria (Table 3 ).

In a landmark analysis performed at three months (and six months) from treatment onset in patients with baseline cytogenetic abnormalities evaluable for CyR, achieving hematological response was associated with a significant OS advantage (median 21.7 vs 12.4 months, $\mathrm{p}<10^{-4}$, Fig. 1A) but achieving cytogenetic response (median 18.63 months vs 15.7 months, $\mathrm{p}=0.15$, Fig. $1 \mathrm{~B}$ ) had no influence on OS. In patients without morphological response, the achievement of any cytogenetic response was not associated with any survival advantage.

For each cytogenetic abnormality tested, the achievement of CCyR had no impact on OS compared to patients with the same cytogenetic abnormality at onset who did not achieve any CCyR. Moreover, survival of patients with abnormal cytogenetics who achieved CCyR was significantly shorter than that of patients with normal karyotype. However, when the analysis was restricted to low blast count patients (i.e. $<20 \%, \mathrm{n}=135)$, CCyR was associated with better OS (21.7 vs 15.7 months for patients who did not achieve CCyR, $p=0.017$, Fig. 1C).

\section{Discussion}

Our study is, to our knowledge, the largest study analyzing the impact of baseline cytogenetic characteristics and cytogenetic response on response and survival, in higher risk MDS patients treated with AZA.

For ORR, we found that patients with $3 q$ abnormalities or complex karyotype had significantly lower ORR when the analysis was restricted to patients with less than $20 \%$ bone marrow blasts, while all other cytogenetic abnormalities had a similar ORR as patients with normal 
Table 2

Response and survival according to cytogenetic features.

\begin{tabular}{|c|c|c|c|c|c|c|c|}
\hline Cytogenetic abnormality & $\mathrm{N}$ & ORR (\%) & P vs NK & CR (\%) & P vs NK & OS (months) & P vs NK \\
\hline Normal Karyotype & 209 & $46.12 \%$ & - & $17.48 \%$ & - & 22.03 & - \\
\hline Other double abn & 26 & $50.0 \%$ & 0.835 & $11.54 \%$ & 0.584 & 17.23 & 0.35 \\
\hline Other single abn & 51 & $43.14 \%$ & 0.755 & $13.73 \%$ & 0.676 & 14.46 & 0.09 \\
\hline Chromosome 7 abn (all) & 227 & $41.78 \%$ & 0.383 & $16 \%$ & 0.700 & 12.3 & $<10^{-4}$ \\
\hline Monosomy 7 (all) & 142 & $39.01 \%$ & 0.225 & $14.18 \%$ & 0.460 & 11.1 & $<10^{-4}$ \\
\hline isolated Monosomy 7 & 29 & $44.83 \%$ & 1.000 & $10.34 \%$ & 0.432 & 14.7 & 0.05 \\
\hline Monosomy $7+1$ abn & 20 & $45.00 \%$ & 1.000 & $15.00 \%$ & 1.000 & 11.5 & 0.04 \\
\hline Del7q (all) & 51 & $46.12 \%$ & 0.639 & $24.00 \%$ & 0.314 & 15.8 & 0.63 \\
\hline Isolated del(7q) & 13 & $46.15 \%$ & 1.000 & $23.08 \%$ & 0.707 & 16.23 & 0.68 \\
\hline $\operatorname{del}(7 q)+1$ abn & 9 & $55.56 \%$ & 0.736 & $44.44 \%$ & 0.064 & 20.2 & 0.39 \\
\hline Trisomy 8 (all) & 107 & $47.66 \%$ & 0.812 & $22.43 \%$ & 0.294 & 16 & 0.11 \\
\hline Isolated tri8 & 41 & $41.46 \%$ & 0.611 & $14.63 \%$ & 0.821 & 17.63 & 0.55 \\
\hline Chromosome 5 abn (all) & 206 & $48.29 \%$ & 0.693 & $18.05 \%$ & 0.898 & 10.3 & $<10^{-4}$ \\
\hline del5q (all) & 126 & $47.58 \%$ & 0.820 & $18.55 \%$ & 0.882 & 10.23 & $<10^{-4}$ \\
\hline Isolated del(5q) & 9 & $77.78 \%$ & 0.089 & $11.11 \%$ & 1.000 & 20.1 & 0.88 \\
\hline $\operatorname{del}(5 q)+1$ abn & 14 & $46.12 \%$ & 0.582 & $17.48 \%$ & 0.718 & 15.03 & 0.41 \\
\hline $\operatorname{Del}(20 q)$ (all) & 47 & $51.06 \%$ & 0.628 & $21.28 \%$ & 0.534 & 15.13333 & 0.03 \\
\hline Isolated del(20q) & 15 & $53.33 \%$ & 0.604 & $13.33 \%$ & 1.00 & 20.8 & 0.47 \\
\hline $\operatorname{Del}(11 q)$ (all) & 24 & $37.50 \%$ & 0.518 & $4.17 \%$ & 0.13 & 15.66 & 0.34 \\
\hline $\operatorname{Del}(11 \mathrm{q})$ isolated & 5 & - & - & - & - & - & - \\
\hline 3q abnormalities (all) & 26 & $19.23 \%$ & 0.011 & $3.85 \%$ & 0.089 & 13.733 & 0.04 \\
\hline Non complex 3q & 11 & $18.18 \%$ & 0.117 & $0 \%$ & 0.218 & 18.83 & 0.42 \\
\hline Complex with $3 q$ & 15 & $20.00 \%$ & 0.061 & $6.67 \%$ & 0.476 & 10.13 & 0.02 \\
\hline Loss of Y (all) & 29 & $43.48 \%$ & 0.830 & $17.39 \%$ & 1.000 & 14.13 & 0.0021 \\
\hline Y loss isolated & 4 & - & & - & & - & - \\
\hline $17 p$ abnormalities (all) & 58 & $48.28 \%$ & 0.882 & $15.52 \%$ & 0.844 & 8.83 & $<10^{-4}$ \\
\hline Complex $\geq 3$ & 246 & $40.98 \%$ & 0.294 & $14.75 \%$ & 0.442 & 11.06 & $<10^{-4}$ \\
\hline Complex monosomal & 185 & $40.22 \%$ & 0.258 & $15.08 \%$ & 0.582 & 10.23 & $<10^{-4}$ \\
\hline Complex non monosomal & 61 & $45.00 \%$ & 1.000 & $15 \%$ & 0.845 & 14.86 & 0.003 \\
\hline
\end{tabular}

ORR, Overall Response Rate; CR, Complete response; OS, Overall Survival; NK, Normal Karyotype; abn, abnormalities.

Table 3

Correlation between Hematological and cytogenetic response in patients with abnormal cytogenetic and evaluable for cytogenetic response.

\begin{tabular}{lllll}
\hline & \multirow{2}{*}{ IWG2006 response } & \multicolumn{2}{l}{ Cytogenetic response } \\
\cline { 3 - 5 } & & Overall & Complete & Partial \\
\cline { 3 - 5 } & 135 & 68 & 56 & 12 \\
ORR & 55 & 35 & 31 & 4 \\
CR & 146 & 22 & 15 & 7 \\
\hline
\end{tabular}

ORR, Overall Response Rate; CR, Complete Response.

karyotype. We didn't observe a response advantage in patients with complex karyotype nor del(17p) (ie probably TP53 mutations), as found in the recent study from Welch and all in AML and MDS patients receiving decitabine [20]. However, beyond the possible differences between aza and decitabine, patients from our cohort might not be exposed at the same level and duration of HMA as patients receiving serial 10-days courses.

Regarding survival, we confirmed in AZA-treated patients the prognostic impact of IPSS-R cytogenetic classification on OS [14,21]. We however identified some differences in several IPSS-R cytogenetic subgroups, established in untreated patients. Indeed, patients with isolated del(7q), non-complex del(7q) or isolated trisomy 8 associated in the IPSS-R classification with a poor outcome, had similar survival as patients with normal cytogenetics, suggesting that azacitidine might overcome the poor prognosis of these cytogenetic features. Finally, a poor OS of patients with del(17p) (8.8 months) was noted in our study, possibly related to the presence of TP53 mutation as other studies found that these mutations are associated with poor survival with AZA treatment $[2,3]$.

In AML treated with intensive chemotherapy, persistence of cytogenetically abnormal cells at CR after induction chemotherapy is a strong predictor for shorter relapse-free survival and overall survival [5]. Whether this finding is true in MDS and AML treated with AZA remained controversial. A recent study by the MD Anderson group, evaluating the impact of cytogenetic response on the outcome in 216 MDS patients treated with hypomethylating agents, found no correlation between hematological and cytogenetic response [12]. We confirmed this finding, as $23 \%$ of cytogenetic responders did not achieve any hematological response. Those findings may be relevant to different mechanisms of action between conventional chemotherapy and hypomethylating agents. The latter may indeed act more by cell reprogramming than by clonal reduction, explaining persistence of cytogenetic abnormalities even in case of hematological response. The absence of impact of cytogenetic response on OS observed in our study is also in line with a recent report showing that the mutation allele burden remained unchanged in chronic myelomonocytic leukemia responding to hypomethylating agents [15].

Our current results suggest for the entire cohort no significant impact of cytogenetic response on OS. This differs from the report of Jabbour et al. where achievement of CCyR was associated with survival improvement, especially in patients without morphological response. Of note this work also included low risk MDS, and patients received mainly Decitabine. On the other hand, in our series of higher risk MDS treated with Azacitidine, when the analysis was restricted to MDS, patients achieving complete cytogenetic response had a significant survival advantage. These observations suggest a disease stage specific effect of hypomethylating agents, as reported in a recent study evaluating the functional effect of azacitidine at different time points during MDS progression [13].

In conclusion, in this large series of higher risk MDS treated with AZA, baseline cytogenetic findings poorly predicted response to AZA but were strong predictors for OS. Cytogenetic response was not correlated to morphological response, and the impact of cytogenetic response on survival was restricted to MDS (ie patients with marrow blasts $<20 \%$ ) 
A

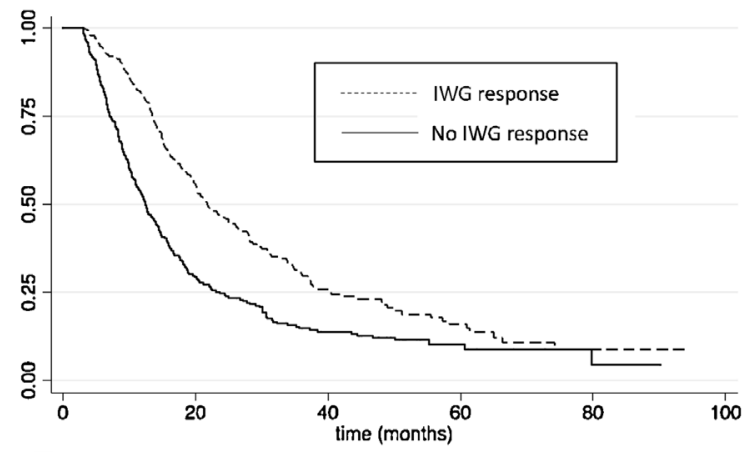

C

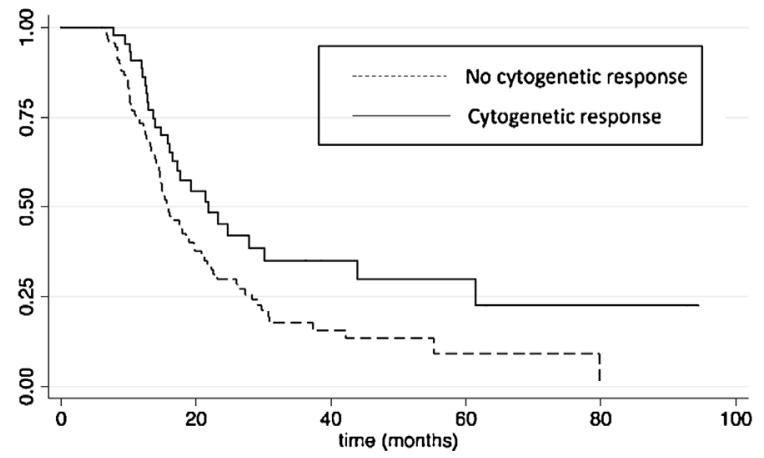

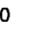

$B$

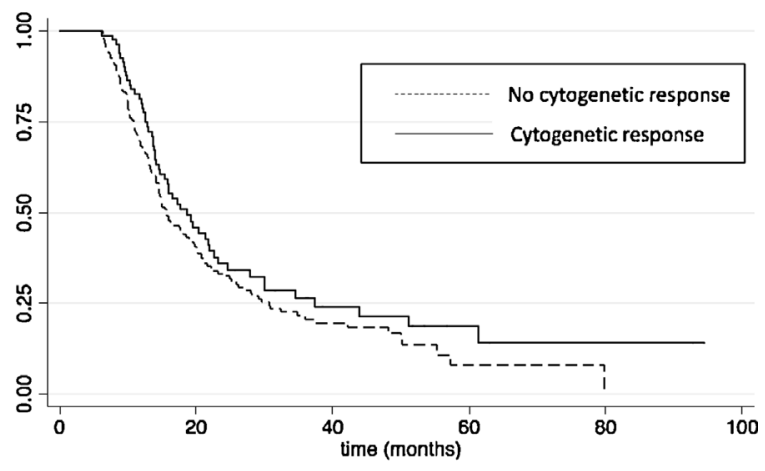

Fig. 1. Overall Survival by landmark analysis in patients evaluable for cytogenetic response: (A) according to IWG response; (B) according to cytogenetic response; (C) according to cytogenetic response in patients less than $20 \%$ of bone marrow blast.

\section{Authorship contributions}

M.S., P.F. and L.A. conceived the study; M.S., and L.A. collected the data; M.S., P.F. and L.A. drafted the manuscript; V.E. reviewed the cytogenetic; L.A. did the statistical analysis; M.S., R.K., M.S., T.P., T.C., V.S., E.G., A.S., N.A., S.H., V.E., A.L., P.F. and L.A. treated the patients, collected the data and approved the manuscript.

\section{Conflict of interest disclosures}

Consultant or Advisory Role: M. Sekeres, Celgene; A. List, Celgene.

Honoraria: A. List, Celgene; E. Gyan, Sanofi and Janssen.

\section{Research funding}

M. Sekeres, Edward P. Evans Foundation; T. Prebet, Celgene; E. Gyan, Celgene and Roche; L. Ades, Celgene.

\section{Acknowledgments}

We thank all physicians who enrolled patients in this study and all investigators of the GFM group.

\section{References}

[1] L. Ades, R. Itzykson, P. Fenaux, Myelodysplastic syndromes, Lancet 383 (2014) 2239-2252.

[2] C. Bally, L. Ades, A. Renneville, M. Sebert, V. Eclache, C. Preudhomme, M.J. Mozziconacci, H. de The, J. Lehmann-Che, P. Fenaux, Prognostic value of TP53 gene mutations in myelodysplastic syndromes and acute myeloid leukemia treated with azacitidine, Leuk. Res. 38 (2014) 751-755.

[3] R. Bejar, A. Lord, K. Stevenson, M. Bar-Natan, A. Perez-Ladaga, J. Zaneveld, H. Wang, B. Caughey, P. Stojanov, G. Getz, G. Garcia-Manero, H. Kantarjian, R. Chen, R.M. Stone, D. Neuberg, D.P. Steensma, B.L. Ebert, TET2 mutations predict response to hypomethylating agents in myelodysplastic syndrome patients, Blood 124 (2014) 2705-2712.

[4] D.A. Breems, W.L. Van Putten, G.E. De Greef, S.L. Van Zelderen-Bhola, K.B. GerssenSchoorl, C.H. Mellink, A. Nieuwint, M. Jotterand, A. Hagemeijer, H.B. Beverloo,
B. Lowenberg, Monosomal karyotype in acute myeloid leukemia: a better indicator of poor prognosis than a complex karyotype, J. Clin. Oncol. 26 (2008) 4791-4797.

[5] X. Chen, H. Xie, B.L. Wood, R.B. Walter, J.M. Pagel, P.S. Becker, V.K. Sandhu, J.L. Abkowitz, F.R. Appelbaum, E.H. Estey, Relation of clinical response and minimal residual disease and their prognostic impact on outcome in acute myeloid leukemia, J. Clin. Oncol. 33 (2015) 1258-1264.

[6] B.D. Cheson, P.L. Greenberg, J.M. Bennett, B. Lowenberg, P.W. Wijermans, S.D. Nimer, A. Pinto, M. Beran, T.M. de Witte, R.M. Stone, M. Mittelman, G.F. Sanz, S.D. Gore, C.A. Schiffer, H. Kantariian, Clinical application and proposal for modification of the International Working Group (IWG) response criteria in myelodysplasia, Blood 108 (2006) 419-425.

[7] P. Fenaux, G.J. Mufti, E. Hellstrom-Lindberg, V. Santini, C. Finelli, A. Giagounidis, R. Schoch, N. Gattermann, G. Sanz, A. List, S.D. Gore, J.F. Seymour, J.M. Bennett, J. Byrd, J. Backstrom, L. Zimmerman, D. McKenzie, C. Beach, L.R. Silverman, International Vidaza High-Risk, M.D.S.S.S.G, Efficacy of azacitidine compared with that of conventional care regimens in the treatment of higher-risk myelodysplastic syndromes: a randomised, open-label, phase III study, Lancet Oncol. 10 (2009) 223-232.

[8] S.D. Gore, P. Fenaux, V. Santini, J.M. Bennett, L.R. Silverman, J.F. Seymour, E. Hellstrom-Lindberg, A.S. Swern, C.L. Beach, A.F. List, A multivariate analysis of the relationship between response and survival among patients with higher-risk myelodysplastic syndromes treated within azacitidine or conventional care regimens in the randomized AZA-001 trial, Haematologica 98 (2013) 1067-1072.

[9] P. Greenberg, C. Cox, M.M. LeBeau, P. Fenaux, P. Morel, G. Sanz, M. Sanz, T. Vallespi, T. Hamblin, D. Oscier, K. Ohyashiki, K. Toyama, C. Aul, G. Mufti, J. Bennett, International scoring system for evaluating prognosis in myelodysplastic syndromes, Blood 89 (1997) 2079-2088.

[10] P.L. Greenberg, H. Tuechler, J. Schanz, G. Sanz, G. Garcia-Manero, F. Sole, J.M. Bennett, D. Bowen, P. Fenaux, F. Dreyfus, H. Kantarjian, A. Kuendgen, A. Levis, L. Malcovati, M. Cazzola, J. Cermak, C. Fonatsch, M.M. Le Beau, M.L. Slovak, O. Krieger, M. Luebbert, J. Maciejewski, S.M. Magalhaes, Y. Miyazaki, M. Pfeilstocker, M. Sekeres, W.R. Sperr, R. Stauder, S. Tauro, P. Valent, T. Vallespi, A.A. van de Loosdrecht, U. Germing, D. Haase, Revised international prognostic scoring system for myelodysplastic syndromes, Blood 120 (2012) 2454-2465.

[11] D. Haase, U. Germing, J. Schanz, M. Pfeilstocker, T. Nosslinger, B. Hildebrandt, A. Kundgen, M. Lubbert, R. Kunzmann, A.A. Giagounidis, C. Aul, L. Trumper, O. Krieger, R. Stauder, T.H. Muller, F. Wimazal, P. Valent, C. Fonatsch, C. Steidl, New insights into the prognostic impact of the karyotype in MDS and correlation with subtypes: evidence from a core dataset of 2124 patients, Blood 110 (2007) 4385-4395.

[12] E. Jabbour, P. Strati, M. Cabrero, S. O'Brien, F. Ravandi, C. Bueso-Ramos, Q. Wei, J. Hu, S. Abi Aad, N.J. Short, C. Dinardo, N. Daver, T. Kadia, W. Wierda, Y. Wei, S. Colla, G. Borthakur, J. Cortes, Z. Estrov, H. Kantarjian, G. Garcia-Manero, Impact of achievement of complete cytogenetic response on outcome in patients with myelodysplastic syndromes treated with hypomethylating agents, Am. J. Hematol. 92 (2017) 351-358.

[13] A.G. Kotini, C.J. Chang, A. Chow, H. Yuan, T.C. Ho, T. Wang, S. Vora, A. Solovyov, C. Husser, M. Olszewska, J. Teruya-Feldstein, D. Perumal, V.M. Klimek, 
A. Spyridonidis, R.K. Rampal, L. Silverman, E.P. Reddy, E. Papaemmanuil, S. Parekh, B.D. Greenbaum, C.S. Leslie, M.G. Kharas, E.P. Papapetrou, StageSpecific human induced pluripotent stem cells map the progression of myeloid transformation to transplantable leukemia, Cell Stem Cell 20 (2017) 315-328 (e317).

[14] M. Lamarque, S. Raynaud, R. Itzykson, S. Thepot, B. Quesnel, F. Dreyfus, O.B. Rauzy, P. Turlure, N. Vey, C. Recher, C. Dartigeas, L. Legros, J. Delaunay, S. Visanica, A. Stamatoullas, P. Fenaux, L. Ades, The revised IPSS is a powerful tool to evaluate the outcome of MDS patients treated with azacitidine: the GFM experience, Blood 120 (2012) 5084-5085.

[15] J. Merlevede, N. Droin, T. Qin, K. Meldi, K. Yoshida, M. Morabito, E. Chautard, D. Auboeuf, P. Fenaux, T. Braun, R. Itzykson, S. de Botton, B. Quesnel, T. Commes, E. Jourdan, W. Vainchenker, O. Bernard, N. Pata-Merci, S. Solier, V. Gayevskiy, M.E. Dinger, M.J. Cowley, D. Selimoglu-Buet, V. Meyer, F. Artiguenave,

J.F. Deleuze, C. Preudhomme, M.R. Stratton, L.B. Alexandrov, E. Padron, S. Ogawa, S. Koscielny, M. Figueroa, E. Solary, Mutation allele burden remains unchanged in chronic myelomonocytic leukaemia responding to hypomethylating agents, Nat. Commun. 7 (2016) 10767.

[16] G.J. Mufti, S.D. Gore, V. Santini, P. Fenaux, L.R. Silverman, A. Hagemeijer, B. Skikne, E. Hellstrom-Lindberg, J.F. Seymour, C.L. Beach, J. Backstrom, I. Fernando, Influence of karyotype on overall survival in patients with higher-Risk myelodysplastic syndrome treated with azacitidine or a conventional care regimen, Blood 114 (2009) 1755.

[17] K. Raj, A. John, A. Ho, C. Chronis, S. Khan, J. Samuel, S. Pomplun, N.S. Thomas, G.J. Mufti, CDKN2 B methylation status and isolated chromosome 7 abnormalities predict responses to treatment with 5-azacytidine, Leukemia 21 (2007) 1937-1944.

[18] J. Schanz, H. Tuchler, F. Sole, M. Mallo, E. Luno, J. Cervera, I. Granada, B. Hildebrandt, M.L. Slovak, K. Ohyashiki, C. Steidl, C. Fonatsch, M. Pfeilstocker, T. Nosslinger, P. Valent, A. Giagounidis, C. Aul, M. Lubbert, R. Stauder, O. Krieger, G. Garcia-Manero, S. Faderl, S. Pierce, M.M. Le Beau, J.M. Bennett, P. Greenberg, U. Germing, D. Haase, New comprehensive cytogenetic scoring system for primary myelodysplastic syndromes (MDS) and oligoblastic acute myeloid leukemia after MDS derived from an international database merge, J. Clin. Oncol. 30 (2012) $820-829$.

[19] A. Simons, L.G. Shaffer, R.J. Hastings, Cytogenetic nomenclature: changes in the ISCN 2013 compared to the 2009 edition, Cytogenet. Genome Res. 141 (2013) 1-6.

[20] J.S. Welch, A.A. Petti, C.A. Miller, C.C. Fronick, M. O'Laughlin, R.S. Fulton, R.K. Wilson, J.D. Baty, E.J. Duncavage, B. Tandon, Y.S. Lee, L.D. Wartman, G.L. Uy, A. Ghobadi, M.H. Tomasson, I. Pusic, R. Romee, T.A. Fehniger, K.E. StockerlGoldstein, R. Vij, S.T. Oh, C.N. Abboud, A.F. Cashen, M.A. Schroeder, M.A. Jacoby, S.E. Heath, K. Luber, M.R. Janke, A. Hantel, N. Khan, M.J. Sukhanova, R.W. Knoebel, W. Stock, T.A. Graubert, M.J. Walter, P. Westervelt, D.C. Link, J.F. DiPersio, T.J. Ley, TP53 and decitabine in acute myeloid leukemia and myelodysplastic syndromes, N. Engl. J. Med. 375 (2016) 2023-2036.

[21] A.M. Zeidan, J.W. Lee, T. Prebet, P. Greenberg, Z. Sun, M. Juckett, M.R. Smith, E. Paietta, J. Gabrilove, H.P. Erba, M.S. Tallman, S.D. Gore, Eastern Cooperative Oncology Group, North American Leukemia intergroup, Comparison of the prognostic utility of the revised International Prognostic Scoring System and the French Prognostic Scoring System in azacitidine-treated patients with myelodysplastic syndromes, Br. J. Haematol. 166 (2014) 352-359. 